\title{
Case Reports - the CARE Statement
}

Case reports are a very frequent form of publication in the dental literature, presenting clinical observations collected by clinicians and clinical teams. They are helpful in identifying adverse effects and for describing rare diseases and unusual conditions, or describing new techniques. However there is a great deal of variation in the quality of these reports.

The CARE statement consists of a 13-item checklist that outlines the key elements that should be included in a good case report. The items are:

- Title

- Keywords

- Abstract

- Introduction

- Patient information

- Clinical findings

- Timeline

- Diagnostic assessment

- Therapeutic intervention

- Follow-up and outcome

- Discussion

- Patient perspective

- Informed consent.

The checklist can be accessed on line at The Case Reports website (http://www. care-statement.org/ ). In addition to the checklist the website provides a case report writing template and links to other resources. As with the SPIRIT statement the CARE statement can be found on the Equator (Enhancing the QUAlity and Transparency Of health Research) Network website (www. equator-network.org) with a wide range of other useful guidance documents.

Further details regarding the CARE statement can be found in the paper published by the CARE Group, which has been published in a number of journals. ${ }^{1-6}$

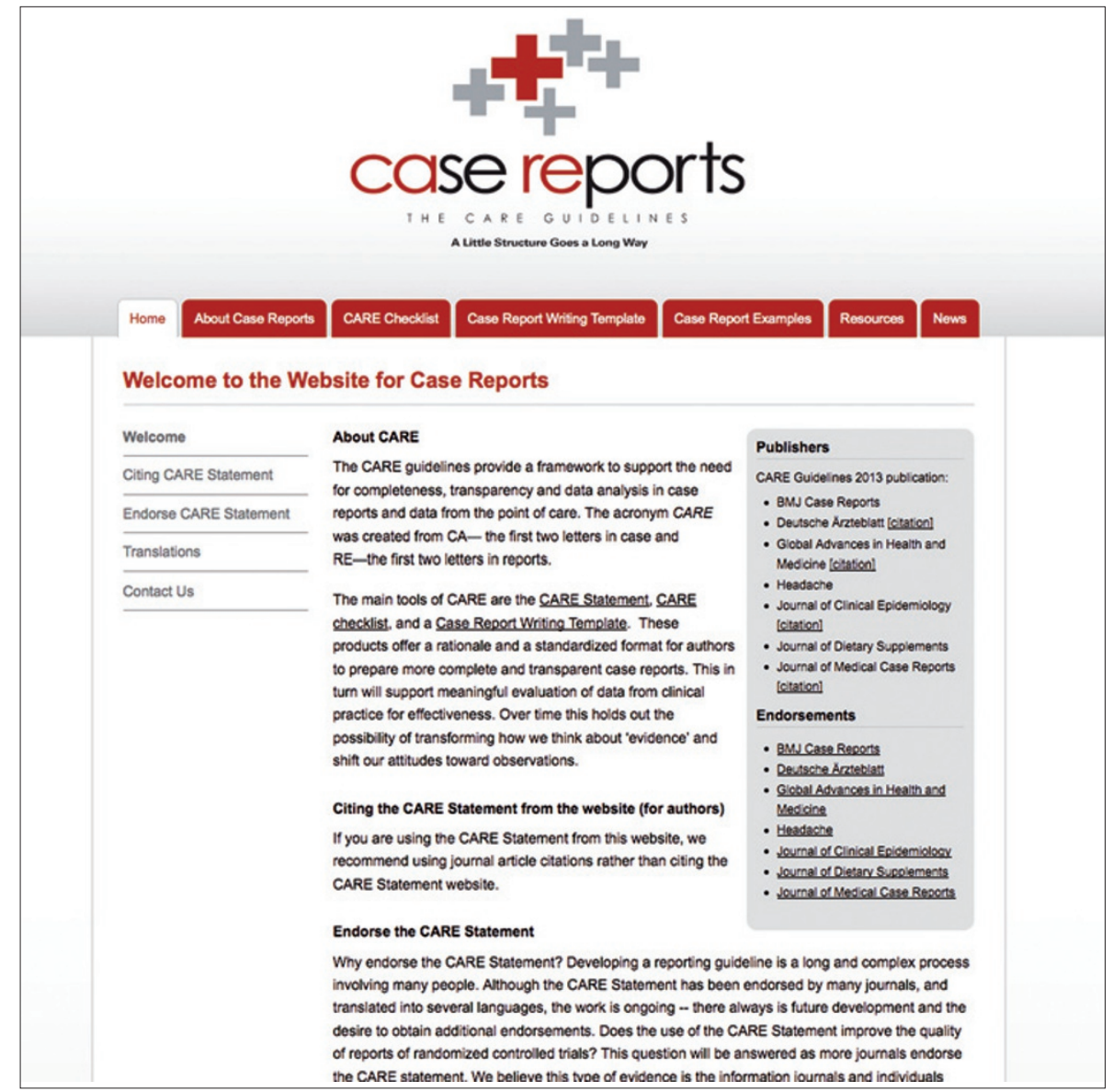

Figure 1. The Case Reports Website - home page

1. Gagnier JJ, Kienle G, Altman DG, Moher D, Sox $H$, Riley D; CARE Group. The CARE guidelines: consensus-based clinical case reporting guideline development. BMJ Case Rep 2013; Oct 23; 2013. doi:pii: bcr2013201554. 10.1136/bcr-2013-201554. PubMed PMID: 24155002.

2. Gagnier IJ, Riley D, Altman DG, Moher D, Sox $\mathrm{H}$, Kienle G; CARE Group. The CARE guidelines: consensus-based clinical case reporting guideline development. Dtsch Arztebl Int 2013; 110: 603-608. doi: 10.3238/arztebl.2013.0603. Epub 2013 Sep 13. PubMed PMID: 24078847; PubMed Central PMCID: PMC3784031.

3. Gagnier J], Kienle G, Altman DG, Moher D, Sox H, Riley D; CARE Group. The CARE guidelines: consensusbased clinical case report guideline development. J Clin Epidemiol 2014; 67: 46-51. doi: 10.1016/j. jclinepi.2013.08.003. Epub 2013 Sep 12. PubMed PMID: 24035173.

4. Gagnier JJ, Kienle G, Altman DG, Moher D, Sox $\mathrm{H}$, Riley D; CARE Group. The CARE guidelines: consensus-based clinical case reporting guideline development. I Med Case Rep 2013; 7: 223. doi: 10.1186/1752-1947-7-223. PubMed PMID: 24228906.

5. Gagnier JJ, Kienle G, Altman DG, Moher D, Sox H, Riley D; CARE Group*. The CARE Guidelines: Consensus-based Clinical Case Report Guideline Development. J Diet Supp/ 2013; 10: 381-390. doi: 10.3109/19390211.2013.830679. PubMed PMID: 24237192.

6. Gagnier JJ, Kienle G, Altman DG, Moher D, Sox $H$, Riley D; CARE Group*. The CARE Guidelines: Consensus-based Clinical Case Report Guideline Development. Global Adv Health Med. 2013; 2: 38-43. (http://www.gahmj.com/doi/abs/10.7453/ gahmj.2013.008)

Evidence-Based Dentistry (2013) 14, 121. doi:10.1038/sj.ebd.6400974 